\title{
Cytology Specimen Collection Procedure
}

National Cancer Institute

\section{Source}

National Cancer Institute. Cytology Specimen Collection Procedure. NCI Thesaurus. Code C38113.

Procedures for the collection and/or preparation of biological specimens for light microscopy examination. 